\title{
Characterization of $\mathrm{BaTiO}_{3}$ piezoelectric perovskite material for multilayer actuators
}

\author{
MAGDALENA GROMADA ${ }^{1}$, MOJTABA BIGLAR ${ }^{2}$, TOMASZ TRZEPIECIŃSKI $^{2, *}$ (D) and \\ FELIKS STACHOWICZ \\ ${ }^{1}$ Institute of Power Engineering, Ceramic Department CEREL, Research Institute, 36-040 Boguchwała, Poland \\ ${ }^{2}$ Department of Materials Forming and Processing, Faculty of Mechanical Engineering and Aeronautics, Rzeszow \\ University of Technology, 35-959 Rzeszów, Poland \\ *Author for correspondence (tomtrz@prz.edu.pl)
}

MS received 13 April 2016; accepted 26 August 2016; published online 28 July 2017

\begin{abstract}
In this study, we present the results of the manufacturing of $\mathrm{BaTiO}_{3}$ powder, which is meant for use in stackeddisk multilayer actuator production. The solid-state technique was used for powder preparation. The properties of barium titanate material, at each stage of its fabrication (powder, granulate, sintered material), influencing on its application for the stacked-disk multilayer actuator were determined. Particularly, the four parameters of $\mathrm{BaTiO}_{3}$ sinter affecting on the usability properties of actuators, not found before in the literature, were estimated. Parameters characterizing the extent of material sintering, SEM microstructures and electric properties of the fabricated pellets are presented and discussed. The dilatometric curve was executed using the high temperature dilatometer to determine at which temperature barium titanate pellets and beams should be sintered to receive full dense sinters. Parameters characterizing the extent of material sintering: the apparent density, the apparent porosity and the water absorbability were estimated. Finally, the problem of metal layer deposition on barium titanate ceramics during actuator fabrication is considered.
\end{abstract}

Keywords. Actuators; perovskites; piezoelectric properties; sintering.

\section{Introduction}

The barium titanate $\left(\mathrm{BaTiO}_{3}\right)$ compound is the most intensively studied perovskite material because of its wide use in the ceramics and electronics industries [1,2]. Barium titanate (BT) is a useful and technologically important material as well, owing to its ferroelectric behaviour at and above room temperature $\left(T_{\mathrm{c}} \sim 393 \mathrm{~K}\right)$ [1]. The dielectric properties of $\mathrm{BaTiO}_{3}$ are controlled by purity and microstructure, which are dependent on the methods of preparation [3-5]. Controlling the phase, composition homogeneity, particle size and monodispersity are other concerns in developing techniques for synthesizing barium titanate [6].

Barium titanate powders are manufactured at high temperatures by solid-state reaction or from chemically derived precursors [7]. These methods produce large, non-uniform and agglomerated particles that have to be milled and heattreated to obtain the particle size required $(0.5-1.5 \mu \mathrm{m})$ to fabricate reliable multilayer ceramic capacitors [8]. The traditional solid-state method used in our research for $\mathrm{BaTiO}_{3}$ synthesis has strict criteria with regard to particle size and purity of the raw material, although it is easy to produce non-homogeneous powders as well [9]. This is significant as the synthesis of ceramic materials requires fine-grained highly pure ceramics $[10,11]$. The advantages of the solidstate reaction used in mass production are its simplicity, precise stoichiometric control and low cost, with the main disadvantage being that the high calcining temperature results in very large and non-uniform grain sizes $[11,12]$. As a consequence, this method does not allow the production of materials with a high dielectric constant [12]. To eliminate the disadvantages of the solid-state reaction, a variety of novel wet chemical synthesis methods have been developed [13-15]. One approach used to influence initial powder microstructure and sintering properties of the material is to mechanically activate the powder using a high-energy ball milling process $[16,17]$. The mechanical activation of raw materials during the powder preparation process using a high-energy milling process is one of the most effective methods for obtaining highly dispersed powders. The decrease of particle size leads to the initiation of a solid-state reaction at lower temperatures $[16,18]$. The sintering of the mechanically activated $\mathrm{BaTiO}_{3}$ took place in three stages; with one sintering mechanism (grain boundary diffusion) compared to the non-activated $\mathrm{BaTiO}_{3}$ where there was only one stage with a volume diffusion mechanism [19]. Pavlović et al [17] investigated the evolution of the microstructure during nonisothermal sintering of barium titanate and the influence of mechanical activation on the electrical properties. The results indicated that mechanical activation and sintering conditions have a significant influence on the dielectric properties of the specimens. 
The dielectric constant, insulation resistance, dielectric loss and breakdown field strength are important engineering parameters for ceramic capacitors. The maximum voltage withstanding ability of a ceramic capacitor is governed mainly by the microstructure uniformity and average grain size [20]. The degree of polarizability of a material is identified by the term 'dielectric constant' or as 'relative permittivity'. Materials with high dielectric constants are mostly used in capacitors. In contrast, materials with low dielectric constants are used for electrical insulator applications [7]. When temperature and frequency vary, the dielectric constant and loss tangent become unsuitable [21]. The dielectric constant is also affected by the frequency of the applied electric field impinging on the material. It is necessary to draw down the Curie temperature to obtain a higher dielectric constant at room temperature [22]. The dielectric loss results from several mechanisms, such as electronic polarization, ion migration and ion vibration. In ceramics, the most important mechanism is ion migration, which is affected by temperature and frequency. The losses due to ion migration increase at low frequencies along with temperature increases [23]. Newnham and Troiler-Mckinstry [24] expected the variation of dielectric properties with decreasing size of barium titanate particles to closely follow the magnetic analogue.

Pure $\mathrm{BaTiO}_{3}$ exhibits a great change in dielectric constant close to the transition temperature [7]. To modify the properties and to widen the number of potential applications the $\mathrm{BaTiO}_{3}$ is doped with impurities. Addition of $\mathrm{PbTiO}_{3}$ increases the transformation (Curie) temperature [23]. Excess of titanium dioxide increases the solubility limit of cerium dioxide in barium titanate [25]. The niobium had a prominent influence on the dielectric properties [26]. Benlahrache et al [27] found that the addition of $\mathrm{NaNbO}_{3}$ causes a considerable change in the microstructure and an increase in density and dielectric constant. It should be pointed out that the Curie constant would be quite sensitive to the type and concentration of the additives in $\mathrm{BaTiO}_{3}$ samples [28].

Piezoelectric ceramics possess good electromechanical properties that are exploited in applications, such as actuators and sensors $[29,30]$. The electrical properties of ceramic materials are a direct result of their microstructure [31,32], whereas it is well known that there is a connection between microstructure and type of porosity, grain size distribution and second-phase content $[33,34]$. A piezoelectric grain-size effect similar to the dielectric grain-size effect observed in unpoled $\mathrm{BaTiO}_{3}$ ceramics may be expected in poled $\mathrm{BaTiO}_{3}$ ceramics [35]. Generally, the properties of $\mathrm{BaTiO}_{3}$ depend on the synthesis method and sintering regime $[2,36]$.

In this study, we analyse the manufacture of $\mathrm{BaTiO}_{3}$ powder destined for use in stacked-disk multilayer actuator production, presenting the results of investigations undertaken at each step of the powder preparation process, including granulation of material and sintering. Parameters characterizing the extent of material sintering, SEM microstructures and electric properties of the fabricated pellets are also presented and discussed.

\section{Experimental}

\subsection{Synthesis of $\mathrm{BaTiO}_{3}(\mathrm{BT})$ perovskite material by solid state}

BT perovskite powder was manufactured from $288.15 \mathrm{~g}$ of $\mathrm{TiO}_{2}\left(99 \%\right.$ purity, Kronos) and $711.85 \mathrm{~g}$ of $\mathrm{BaCO}_{3}(99.5 \%$ purity, Chempur). The set of raw materials was initially mixed in the polyethylene beaker and then $1000 \mathrm{ml}$ of isopropyl alcohol was added. The received slurry was mixed and poured to the mixer mill with working chamber of $\varnothing 135 \times 180 \mathrm{~mm}$, where it was milled for $2 \mathrm{~h}$ with the rotary at $280 \mathrm{~min}^{-1}$. Zirconia balls of approximately $3 \mathrm{~mm}$ diameter and $4.5 \mathrm{~kg}$ weight were employed as a grinding medium. The slurry obtained in this manner was dried in a drier at $70^{\circ} \mathrm{C}$, with the calcination of the obtained powder carried out in an electric furnace at the maximal temperature of $1100^{\circ} \mathrm{C}$ for $8 \mathrm{~h}$, according to the calcination plan shown in table 1 .

The above process produced $756 \mathrm{~g}$ of $\mathrm{BaTiO}_{3}$ powder after the first calcination. This powder together with $800 \mathrm{ml}$ of isopropanol was then milled again for $2 \mathrm{~h}$, followed by calcination of the obtained powder in the electric furnace at $1100^{\circ} \mathrm{C}$ for $8 \mathrm{~h}$, according to the presented sintering curve. This second calcination cycle produced barium titanate powder that was milled for a third time for $2 \mathrm{~h}$. The third calcination of the obtained powder to produce $\mathrm{BaTiO}_{3}$ was undertaken under the same conditions as employed in the previous two cycles.

In the second stage, an abundant supply of barium titanate powder made from $5 \mathrm{~kg}$ of raw materials was prepared. Five lots of $1 \mathrm{~kg}$ weight of raw materials were fabricated, but the mechanical activation and calcination was made two times in order to receive the single phase material. Finally, $3962 \mathrm{~g}$ of barium titanate powder was obtained, which was mechanically activated in a porcelain mill for $8 \mathrm{~h}$ with $3 \mathrm{~kg}$ of balls to make the calcined powder finer.

The X-ray powder diffraction patterns were recorded by X'PertPROX diffractometer equipped with PIXcel detector ( $\mathrm{Cu} \mathrm{K} \alpha$ radiation). The microstructure of $\mathrm{BaTiO}_{3}$ powder was evaluated by using a scanning electron microscopy, SEM/HITACHI S-3400N/2007. The powder morphology was investigated using transmission electron microscopy (TEM, Tesla BS500) operating at a voltage of $60 \mathrm{kV}$. The particle size distribution of $\mathrm{BaTiO}_{3}$ powder was determined using Mastersize 2000 instrument (Melvern Company). The specific surface area and the pore size of the fabricated powder

Table 1. Calcination plan.

\begin{tabular}{lcl}
\hline Temperature $\left({ }^{\circ} \mathrm{C}\right)$ & Time $(\mathrm{h})$ & $\begin{array}{l}\text { Heating/cooling } \\
\text { rate }\left({ }^{\circ} \mathrm{Ch}^{-1}\right)\end{array}$ \\
\hline $20-1100$ & 11 & 100 \\
$1100-1100$ & 8 & 100 \\
$1100-800$ & 3 & Free cooling \\
$800-20$ & & \\
\hline
\end{tabular}



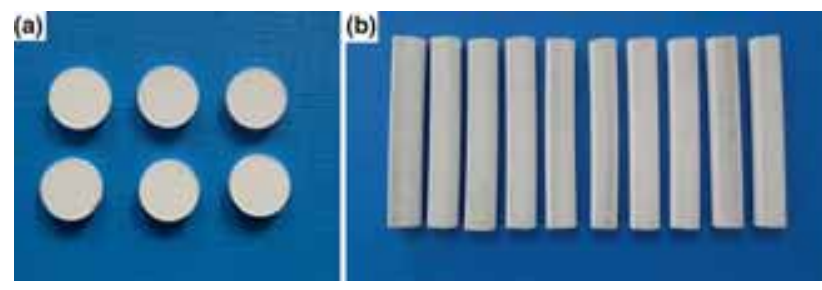

Figure 1. (a) Discs and (b) beams after isostatic pressing formation.

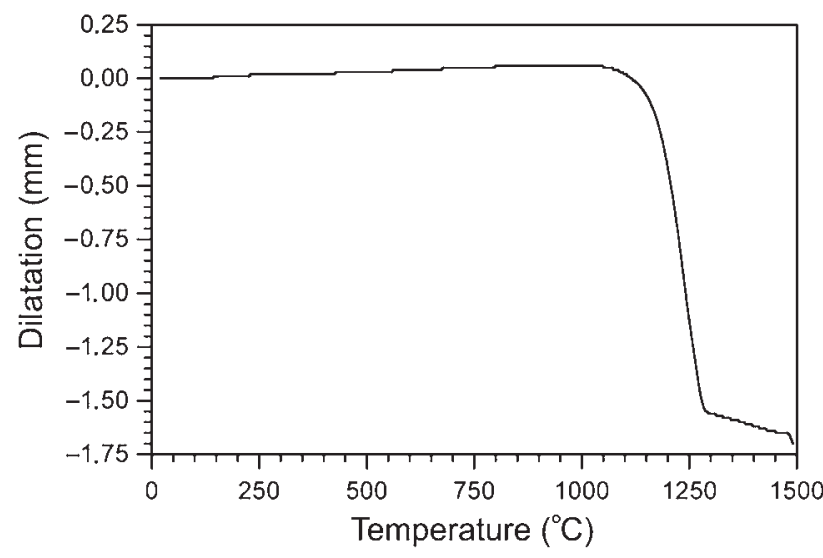

Figure 2. The dilatometric curve of the beam before sintering.

was determined by the low-temperature nitrogen adsorption method (77 K, Quantachrome Autosorb-1).

\subsection{Fabrication of $\mathrm{BaTiO}_{3}$ perovskite granulates}

To improve mouldability, the barium titanate powder was granulated. To this end, $\mathrm{BaTiO}_{3}$ powder of weight $3962 \mathrm{~g}$ was milled with deionized water in a $1: 1$ ratio in a porcelain mill with a $3 \mathrm{~kg}$ ball for $30 \mathrm{~min}$. The following components were then added in the proportion of powder weight: $0.2 \%$ dispex, $0.2 \%$ oil emulsion F15 and $1 \%$ polyvinyl alcohol (PVA). The dispex (BASF) performs a function of dispersing agent, the oil emulsion F15 (Naftochem) is a slide agent and the PVA (Japan Vam \& Poval, Japan) is a plasticizer. The granulation process was performed in a spray drier (Niro) together with a peristaltic pomp type $372^{\circ} \mathrm{C}$ at the inlet temperature of $220^{\circ} \mathrm{C}$, the outlet temperature of $80^{\circ} \mathrm{C}$ and the spray pressure was equal to $40 \mathrm{~mm}$ water column. As a result of the granulation process, $2381 \mathrm{~g}$ of granulate and $1064 \mathrm{~g}$ of dust was obtained.

\subsection{Preparation of pellets and beams from $\mathrm{BaTiO}_{3}$ perovskite granulates}

Pellets were obtained in a mould of external diameter $11.5 \mathrm{~mm}$, with $\mathrm{BaTiO}_{3}$ granulate of weight $0.6 \mathrm{~g}$ and uniaxial pressing under a pressure of $1 \mathrm{MPa}$. The beams were uniaxially pressed under a pressure of $5 \mathrm{MPa}$ in a full mould filled
Table 2. Sintering plan for BT_ 5 pellets.

\begin{tabular}{lcl}
\hline Temperature $\left({ }^{\circ} \mathrm{C}\right)$ & Time $(\mathrm{h})$ & $\begin{array}{l}\text { Heating/cooling } \\
\text { rate }\left({ }^{\circ} \mathrm{Ch}^{-1}\right)\end{array}$ \\
\hline $20-700$ & 2 & 350 \\
$700-1000$ & 6 & 50 \\
$1000-1300$ & 6 & 50 \\
$1300-1300$ & 0.5 & 100 \\
$1300-800$ & 5 & Free cooling \\
$800-20$ & & \\
\hline
\end{tabular}

for beam execution with barium titanate granulate. The green discs and beams obtained in this manner were then isostatically pressed under a pressure of $150 \mathrm{MPa}$. Discs and beams of barium titanate after isostatic pressing are shown in figure 1a and $b$, respectively.

The dilatometric curve was executed using the high temperature dilatometer from BÄHR-Gerätebau $\mathrm{GmbH}$ company to determine at which temperature barium titanate pellets and beams should be sintered to receive full dense sinters. On the basis of the obtained dilatometric curve (figure 2), the maximal sintering temperatures of the pellets were estimated as $1250,1300,1350,1400$ and $1450^{\circ} \mathrm{C}$. Pellets and beams were sintered in the electric furnace according to the five sintering curves. The rate of both heating and cooling was $100^{\circ} \mathrm{C} \mathrm{h}^{-1}$, while the dwell time was $4 \mathrm{~h}$. Hereafter, sintered pellets and beams are denoted as BT_0, BT_1, BT_2, BT_3 and BT_4.

Parameters characterizing the extent of material sintering: the apparent density, the apparent porosity and the water absorbability were estimated by the method, taking advantage of the Archimedes law. The coefficients of linear expansion of barium titanate beams after sintering in the range of temperature from 20 to 600 and $900^{\circ} \mathrm{C}$ were determined using the above mentioned dilatometer. The bending strength of beams was determined by a three-point method from the sintered and not polished samples on the strength testing machine Zwick Roell Z030. The hardness and fracture toughness $\mathrm{K}_{1 \mathrm{C}}$ of sintered material was performed on Vickers hardness testing machine 430/450SVD (Wilson Hardness).

With an aim to achieve a better result in terms of the barium titanate dielectric constant, the sinter microstructure must be improved by increasing the number of smaller grains. This problem can be solved using the thermal treatment of green pellets according to the specially designed sintering curves. On the basis of the work carried out by Miot et al [10], green pellets were sintered in the electric furnace according to the sintering plan shown in table 2. Henceforth, the sintered pellets were denoted as BT_5.

A decrease in the dwell time to $30 \mathrm{~min}$ at the maximal temperature should in this case limit grain growth. Zheng et al [35] proposed that samples should be heated very rapidly to a maximal temperature of $1380^{\circ} \mathrm{C}$, followed by $16 \mathrm{~min}$ dwell time. Samples should then be cooled to $1150^{\circ} \mathrm{C}$ and held at 
Table 3. Sintering plan for BT_6 pellets.

\begin{tabular}{lll}
\hline Temperature $\left({ }^{\circ} \mathrm{C}\right)$ & Time $(\mathrm{h})$ & $\begin{array}{l}\text { Heating/cooling } \\
\text { rate }\left({ }^{\circ} \mathrm{Ch}^{-1}\right)\end{array}$ \\
\hline $20-1380$ & 4.5 & 300 \\
$1380-1380$ & 0.25 & \\
$1380-1150$ & 0.65 & 300 \\
$1150-1150$ & 6 & 100 \\
$1150-800$ & 3.5 & Free cooling \\
$800-20$ & & \\
\hline
\end{tabular}

Table 4. Sintering plan for BT_7 pellets.

\begin{tabular}{lll}
\hline Temperature $\left({ }^{\circ} \mathrm{C}\right)$ & Time & $\begin{array}{l}\text { Heating/cooling } \\
\text { rate }\left({ }^{\circ} \mathrm{Ch}^{-1}\right)\end{array}$ \\
\hline $20-1370$ & $7 \mathrm{~h} 36 \mathrm{~min}$ & 180 \\
$1370-800$ & $3 \mathrm{~h} 10 \mathrm{~min}$ & 180 \\
$800-20$ & & Free cooling \\
\hline
\end{tabular}

this temperature for $6 \mathrm{~h}$, which should stabilize the sintered material. Therefore, green pellets were sintered in the electric furnace according to the sintering plan shown in table 3, producing sintered pellets that were later denoted as BT_6.

Duran et al [37] have alternatively suggested that barium titanate material should be sintered at $1370^{\circ} \mathrm{C}$, but without the application of any dwell time, which should inhibit grain growth. Subsequently, pellets denoted as BT_7 were sintered in the electric furnace according to the sintering plan shown in table 4.

\subsection{Fabrication of barium titanate actuator}

The first stage of actuator fabrication is frequently characterized by the problem of metal layer deposition on barium titanate ceramics. To ensure the most suitable adhesion of layers, pellets were polished using abrasive paper 320, which also enabled the production of the expected pellet thickness of $0.71 \mathrm{~mm}$ and diameter of $9.66 \mathrm{~mm}$. Two commercial products (Technicqll and Chester Molecular Metal Super) developed for metallic layer deposition were applied. Technicqll is a silver-based product, which allows the creation of adhesive layers that conduct an electric current and is characterized by a low resistance equal to $0.01 \Omega$. The second product-Chester Metal Super-is a two-element tixotropic epoxy-metallic composite. Both commercial products were utilized during trials of metallic layer deposition on BT_0 pellets. In the first case, two pellets were bonded by deposition of metallic compositions, while in the second case only the top sides of pellets were treated to observe the quality of the received layers. The treated samples (figure 3 ) were later denoted as BT_0_S for Technicqll and BT_0_M for Chester Molecular Metal Super treatments.

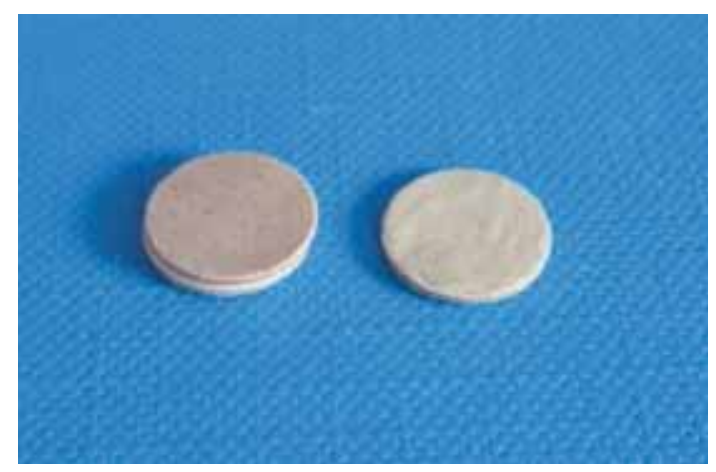

Figure 3. Samples of deposited metallic layers on ceramic pellets for BT_0_S.

\section{Results and discussion}

\subsection{Characterization of barium titanate powder}

XRD patterns of $\mathrm{BaTiO}_{3}$ after the first, second and third activation and calcinations are presented in figure 4. Powder of barium titanate after the first mechanical activation and calcination reveals quite good agreement of peaks with standard powder (figure 4a). The spacing and width of standard and considered powder are very well convergent. The difference in the level of peak intensity is visible and one can notice the shoulder peaks, which originate from the raw materials of barium tinanate that did not fully react during the first mechanical activation and calcination. These shoulder peaks disappear after the second mechanical activation and calcination because the additional treatment improved the phase composition by incorporation of residual raw metal oxides into the structure of the $\mathrm{BaTiO}_{3}$ powder. After the second mechanical activation and calcination (figure 4b), the diffraction pattern of barium titanate powder fully overlaps with the standard powder. The same result is visible for $\mathrm{BaTiO}_{3}$ powder after the third activation and calcination (figure 4c), which is in accordance with expectation. Therefore, one can draw a conclusion that after the second mechanical activation and calcination of barium titanate, the single-phase powder was obtained.

To prove the phase composition of $\mathrm{BaTiO}_{3}$ powder prepared in the second stage, the XRD pattern was performed and the obtained result is presented in figure 5 , from which it follows that the received powder has a single phase without any divergence from the standard spectrum. In addition, an average size of crystallite for $\mathrm{BaTiO}_{3}$ powder of $229 \mathrm{~nm}$ was calculated from XRD patterns using the Scherrer equation.

SEM image on the left hand side of figure 6 shows that the received powder possesses a homogeneous structure and dimension. The greater magnification of powder presented in figure $6 \mathrm{~b}$ allows to estimate the grain size of barium titanate powder as $500 \mathrm{~nm}$. The only few grains visible in this image have the mean size of about $1 \mu \mathrm{m}$. 

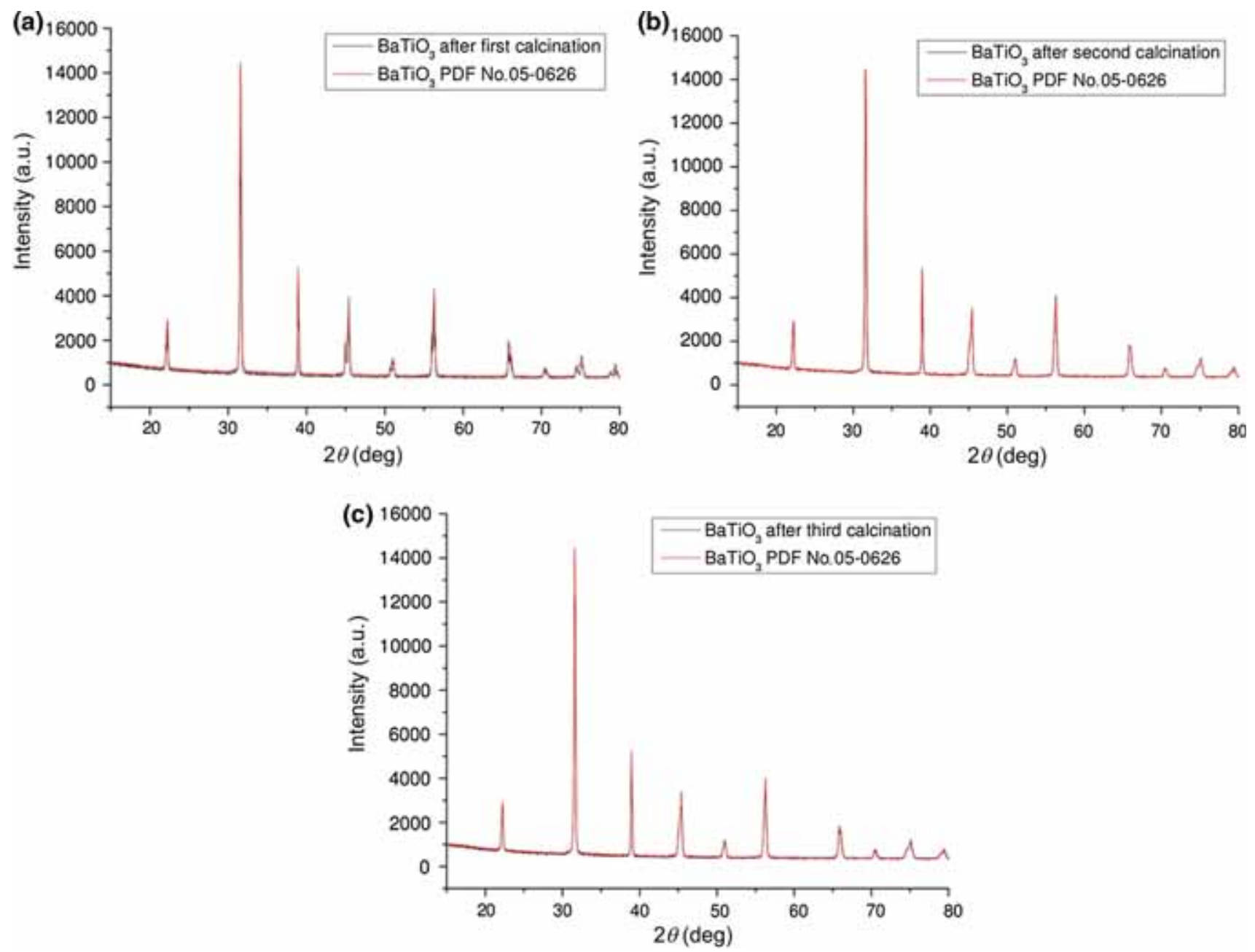

Figure 4. XRD patterns of $\mathrm{BaTiO}_{3}$ powder after (a) first, (b) second and (c) third activation and calcination.

The photos of SEM microstructure are not of high quality, probably because the contrast was not set at the appropriate level. TEM analysis was performed to study the shape and size of powder particles. Figure 7 presents TEM photos of $\mathrm{BaTiO}_{3}$ powder and its particles have regular shape and quite similar size ranging from 200 to $500 \mathrm{~nm}$. The particles size of barium titanate powder presented in photos of SEM and TEM morphology is in good agreement with the result of the average size of crystallite determined from XRD analysis.

As can be seen from figure 8 , the distribution of barium titanate is bimodal and ranges from 0.3 to $80 \mu \mathrm{m}$. The mean particle size of $\mathrm{BaTiO}_{3}$ powder is equal to $1.59 \mu \mathrm{m}$, while the $\mathrm{d}_{10}$ and $\mathrm{d}_{90}$ are equal to 0.66 and $20.64 \mu \mathrm{m}$, respectively. The discrepancy between the results of both SEM microstructure presented in figure 6 and TEM morphology shown in figure 7 together with the particle size distribution of barium titanate powder (figure 8) results from the easy creation of agglomerates. Such a cluster of agglomerates forms particles, which were measured on Mastersize 2000 apparatus and the value of the mean particle size was over three times higher than the separate grain. It should be underlined that Yoon and Lee [38] in their research have used the commercial powder of barium titanate made by solid state of a similar kind to obtain in this approach the mean particle size $1.38 \mu \mathrm{m}$ and a specific surface area of $2.84 \mathrm{~m}^{2} \mathrm{~g}^{-1}$.

The specific surface area of barium titanate powder was equal to $1.87 \mathrm{~m}^{2} \mathrm{~g}^{-1}$, which was a very small value. Moreover, the measurements of low-temperature nitrogen sorption showed that this material exhibited only trace porosity, which confirms insignificant value of pores volumes reaching $0.0001 \mathrm{~cm}^{3} \mathrm{~g}^{-1}$.

\subsection{Characterization of $\mathrm{BaTiO}_{3}$ granulates}

To verify whether the granulation process did not influence the phase composition of barium titanate, the measurement of XRD spectrum was performed. Figure 9 presents the XRD pattern of the granulate, which is very well fitted with the standard spectrum. 


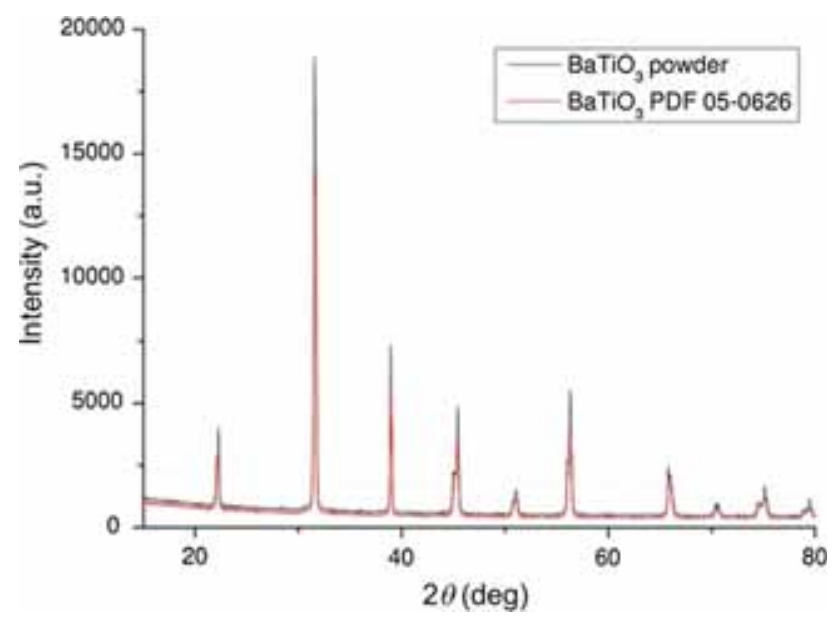

Figure 5. XRD pattern of $\mathrm{BaTiO}_{3}$ powder after second mechanical activation and calcination.
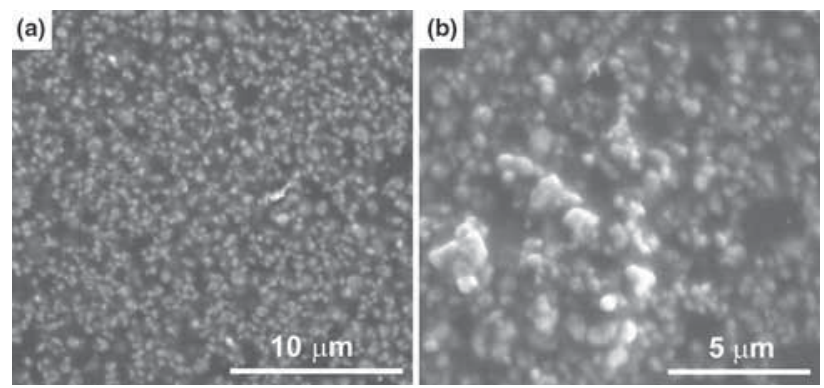

Figure 6. SEM microstructure of $\mathrm{BaTiO}_{3}$ powder in two different magnifications: (a) $\times 4000$ and (b) $\times 6500$.

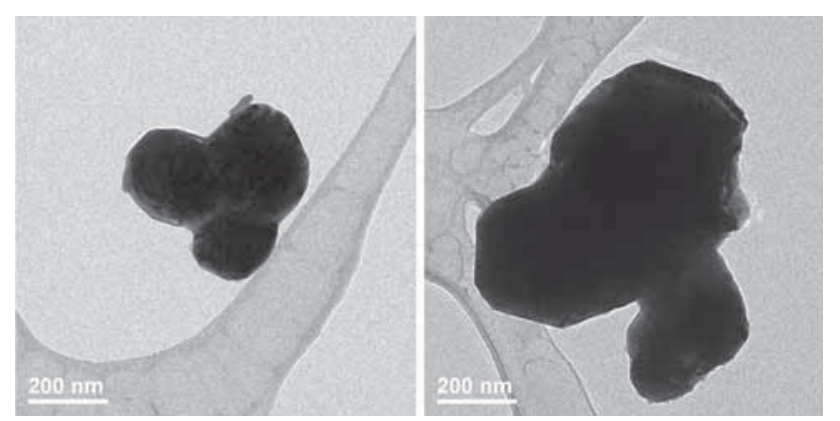

Figure 7. TEM morphology of $\mathrm{BaTiO}_{3}$ powder.

During the granulation process, the water slurry was sprayed in the nozzle and as a result, the filled balls of the dimension from 25 to $35 \mu \mathrm{m}$ was created and presented in figure 10. The granules are built from closely compacted grains of powder. The size of powder grains did not change because the powder was only mixed with additives before the granulation process.

The specific surface area of barium titanate granulate is even smaller than in the case of powder and it is equal to

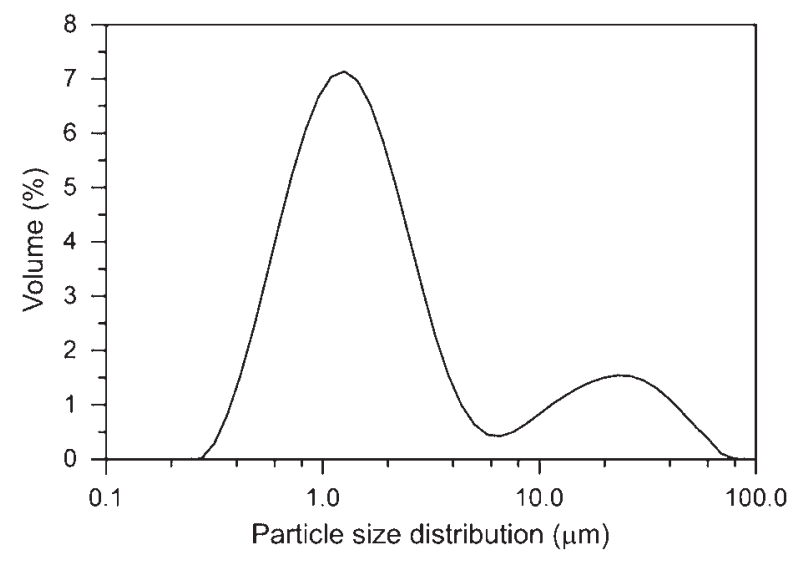

Figure 8. The particle size distribution of $\mathrm{BaTiO}_{3}$ powder.

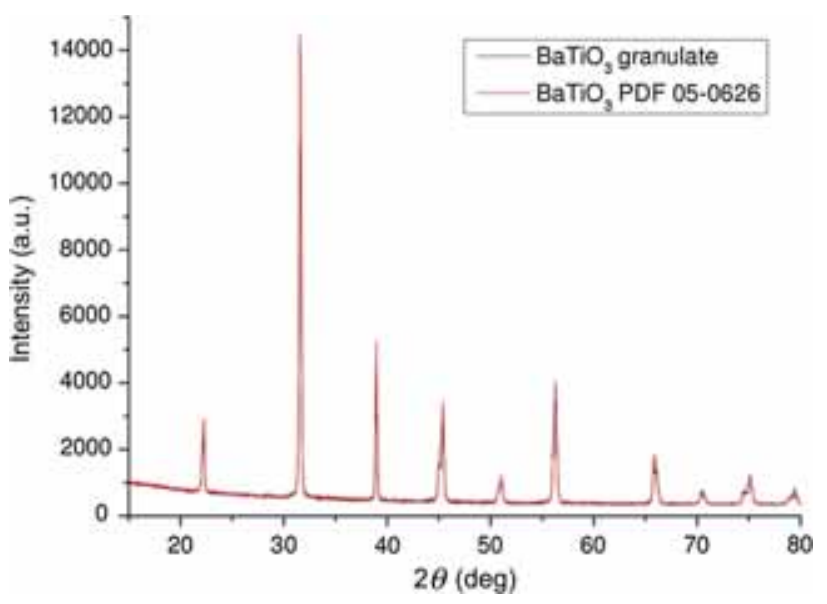

Figure 9. XRD pattern of $\mathrm{BaTiO}_{3}$ granulate.

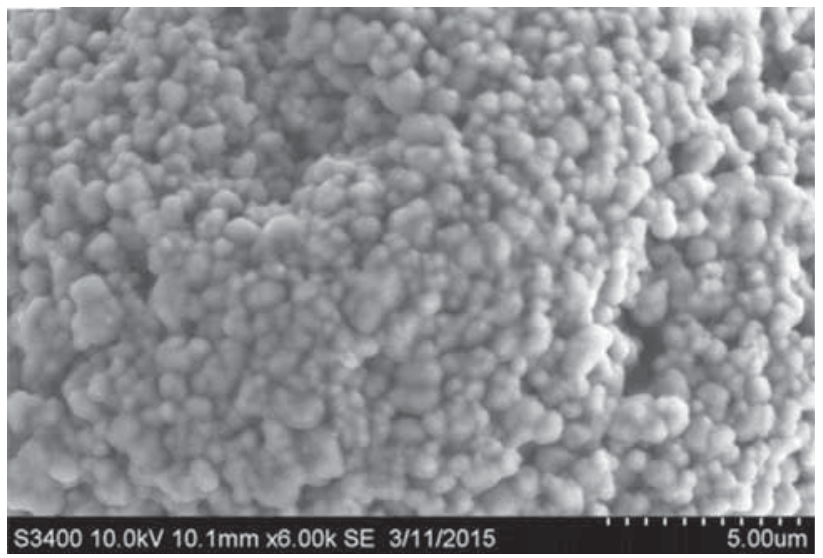

Figure 10. SEM microstructure of $\mathrm{BaTiO}_{3}$ granulate, magnifications $\times 6000$.

$1.18 \mathrm{~m}^{2} \mathrm{~g}^{-1}$. However, the barium titanate granulate possesses the pores volumes three times higher $\left(0.0003 \mathrm{~cm}^{3} \mathrm{~g}^{-1}\right)$ than for powder, which is still a very small value. The result of pores volume of granulate is in good agreement with outcome of the SEM images, on which a small amount of pores are visible. 


\subsection{Characterization of pellets and beams from $\mathrm{BaTiO}_{3}$ perovskite granulates}

The values of water absorbability and the apparent porosity grow together with the maximal sintering temperature as shown in table 5. However, the values of apparent density are quite similar and do not have any tendency.

The theoretical density of sintered $\mathrm{BaTiO}_{3}$ was assumed to equal $6.02 \mathrm{~g} \mathrm{~cm}^{-3}$, based on the lattice constant value [10, 37]. The obtained values of relative density (table 5) are very high but are comparable to those presented by other authors [10,37].

Three selected pellets sintered in three different maximal temperatures $\left(1300,1350\right.$ and $\left.1400^{\circ} \mathrm{C}\right)$ were characterized in the direction of the phase composition (figure 11). As it can be visible, XRD patterns of these pellets are not as perfect as in the case of powder and granulate. Apparently, the materials of pellets have only single phase, peaks are in good agreement with standard, the spacing and width of standard and considered pellets are very well convergent, but there is a difference in the level of peaks intensity.

The next parameter influencing on the possibility of application of piezoelectric material on actuators is the grain size of sintered materials. To determine this feature, photos of SEM microstructure of barium titanate after sintering were prepared.

Figure 12a and b presents the BT_1 pellet surface at two different magnifications, $\times 350$ (figure $12 \mathrm{a}$ ) and $\times 1000$ (figure 12b), in which compact densification can be observed. The microstructure is composed of both large grains with dimensions ranging from 50 to $100 \mu \mathrm{m}$, and smaller examples with dimensions ranging from 1 to $3 \mu \mathrm{m}$. Grain boundaries are very well foreshadowed with only slender pores visible. These results are in agreement with the data for BT_1 pellet densification presented in table 5 and investigations carried out by Yoon and Lee [38] and Wang et al [39].

Images of the fracture surface of $\mathrm{BT}_{-} 1$, as shown in figure $12 \mathrm{c}$ and $\mathrm{d}$, confirm the very good material densification. In this dense microstructure, small pores are observed with dimensions up to a few micrometres. The microstructure of the more highly sintered BT_2, presented in figure $12 \mathrm{e}$ and $\mathrm{f}$, is even more compacted than BT_1; grain boundaries are less visible and no pores are apparent as both the larger and smaller grains fully fill the entire surface. Slightly molten insets are visible on the grain surface.

As presented in figure 13, images of fracture surface of BT_2 pellets reveal dense microstructure with only a few small pores. Moreover, the backscattered electron micrograph confirms the material homogeneity.

Images of BT_3 pellet surface (figure 14) are very similar to BT_2 material, but the grain boundaries are less drawn. Interestingly, the sintering temperature did not considerably increase the size of the grains.

The fracture surface of BT_3 pellet (figure 15) is also similar to those presented before, but there is a difference in pores size. In figure 15 there are two groups of pores-the small one of a slightly smaller size and the greater one of a diameter bigger than visible until now, in the case of BT_1 and BT_2 pellets. These greater pores are probably as a result of the BT_3 pellet swelling, where additionally, the apparent porosity and the water absorbability are slightly increased, which is in accordance with the result presented in table 5.

To verify whether the use of the specially designed sintering curves achieved the expected sintered material grain size at high relative density, SEM photographs of grain microstructure and stage of densification were determined. Figure 16 presents the microstructure of BT_5, BT_6 and BT_7 pellet surfaces at the same magnification and are not shown previous to the photo of BT_0, which because of the lowest maximal sintering temperature (see above a description of the sintering curve for BT_0 material) should produce the smallest grains. Figure 16 reveals that BT_0 and BT_6 pellets share a very similar microstructure in terms of grain size. However, the grain boundaries in BT_6 material are less defined, which will likely worsen the dielectric properties of the material. For materials BT_5 and BT_7, one can observe a greater number of large grains than for BT_0 and BT_6. Based on the microstructure of the obtained sintered materials, the most appropriate for actuator manufacture is BT_0. Moreover, the obtained sinter microstructure is extremely similar to that presented elsewhere in the literature [38,39].

This conclusion can be confirmed by results of materials densification presented in table 6 and for BT_0 material in table 5. The highest relative density at negligible water absorbability and acceptable apparent porosity reveals BT_0 material, which will be considered in the further part as the most suitable material for actuator fabrication. Moreover, the

Table 5. The apparent density, water absorbability and apparent porosity of sintered pellets.

\begin{tabular}{lcccc}
\hline Material & $\begin{array}{c}\text { Water } \\
\text { absorbability (\%) }\end{array}$ & $\begin{array}{c}\text { Apparent } \\
\text { density }\left(\mathrm{g} \mathrm{cm}^{-3}\right)\end{array}$ & $\begin{array}{c}\text { Apparent } \\
\text { porosity (\%) }\end{array}$ & $\begin{array}{c}\text { Relative } \\
\text { density (\%) }\end{array}$ \\
\hline BT_0 & 0.03 & 5.84 & 0.19 & 97.01 \\
BT_1 & 0.05 & 5.82 & 0.28 & 96.68 \\
BT_2 & 0.06 & 5.83 & 0.37 & 96.84 \\
BT_3 & 0.07 & 5.80 & 0.38 & 96.35 \\
BT_4 & 0.09 & 5.87 & 0.50 & 97.51 \\
\hline
\end{tabular}



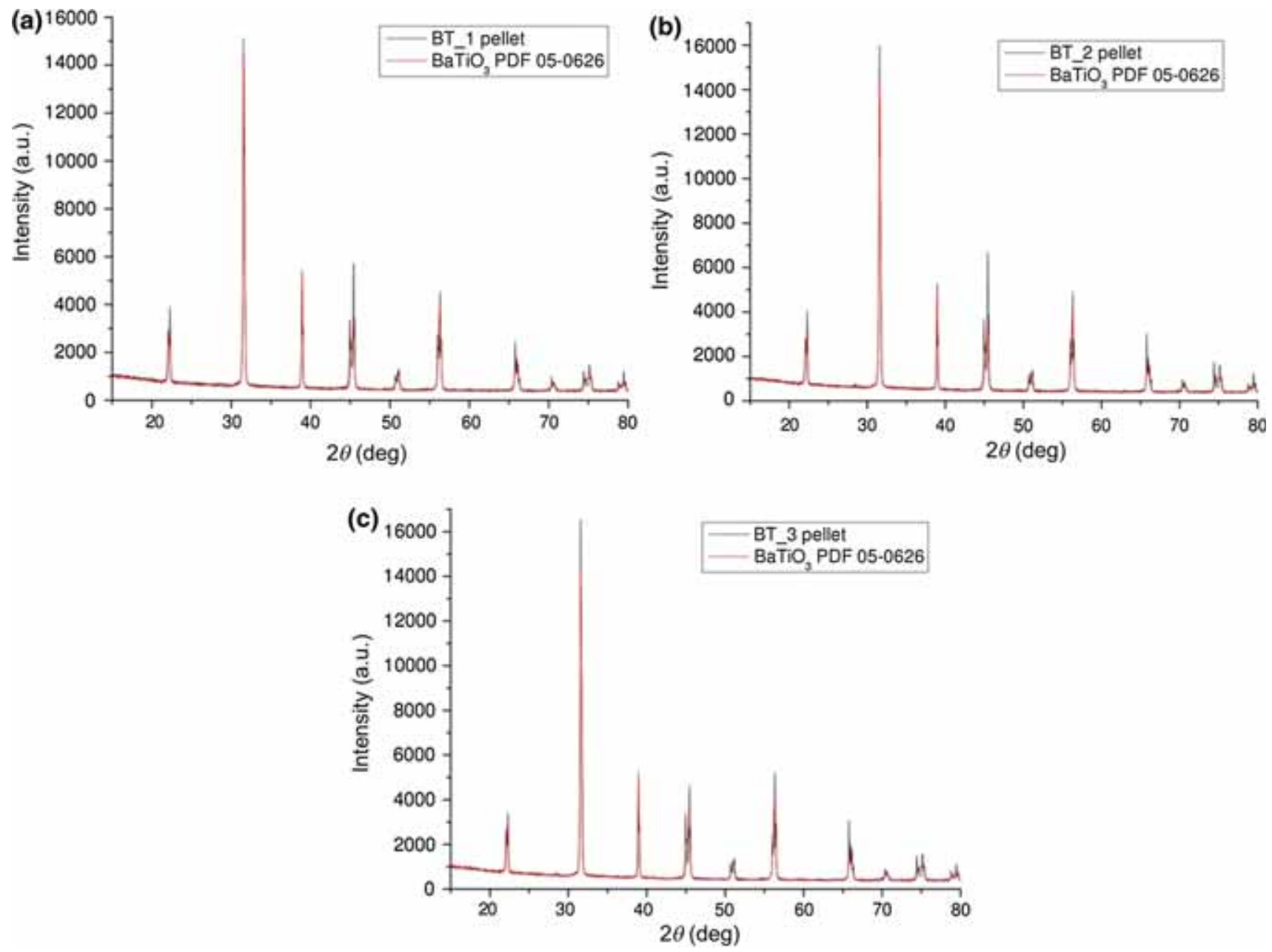

Figure 11. XRD patterns of $\mathrm{BaTiO}_{3}$ pellets sintered in three different maximal temperatures: (a) $1300^{\circ} \mathrm{C},(\mathbf{b}) 1350^{\circ} \mathrm{C}$ and $(\mathbf{c}) 1400^{\circ} \mathrm{C}$.

comparable values of the samples' density in tables 5 and 6 mean that the appropriate high level of materials densification was achieved.

The coefficient of thermal expansion at $600^{\circ} \mathrm{C}$ for BT_0 material was equal to $4.75 \times 10^{-6} \mathrm{~K}^{-1}$, whereas at $900^{\circ} \mathrm{C}$, it has a value of $12.02 \times 10^{-6} \mathrm{~K}^{-1}$. The obtained coefficient of thermal expansion should ensure the silver electrode deposition and sintering at about $600^{\circ} \mathrm{C}$ [35] without any mismatching of thermal behaviours of both barium titanate and silver paint.

The mean value of bending strength for BT_0 beams was determined as 78.1 MPa. The Vickers hardness of BT_0 material was equal to $3.09 \mathrm{GPa}$, whereas the fracture toughness has the value $0.83 \mathrm{MPa} \mathrm{m}{ }^{1 / 2}$.

The electrical properties of BT_0 pellets were then determined, with pellet $\mathrm{AC}$ conductivity measured as a function of frequency at $150^{\circ} \mathrm{C}$ as shown in figure 17 . It is well known that at room temperature conductivity is almost independent of temperature and instead depends strongly on frequency. Analysis of AC conductivity vs. frequency plot (figure 17) reveals that BT_0 conductivity increases with increasing frequency. However, there is a little signature of a plateau in the curve at higher frequencies, beyond the measuring range. It is therefore evident that the linear (dispersion) region represents some sort of relaxation process. The dependence of AC conductivity on frequency may be influenced by carrier transport excited to localized states near the band edge, as well as hopping of the charge carriers through trap sites separated by energy barriers of various heights. In other words, AC conductivity contributes in the form of the hopping of localized and free charge carriers [40].

Particularly, at low temperature, AC conductivity can occur through the carrier motion over a shorter distance between sites in the potential well. In the present study, the AC conductivity for BT_0 was found to be of the order of $10^{-9}$, which is closely related with literature. It is considered that the AC conductivity is contributed by hopping of localized and free charges.

At room temperature, the dielectric constant value for BT_0 pellets was found to decrease with frequency (figure 18). 

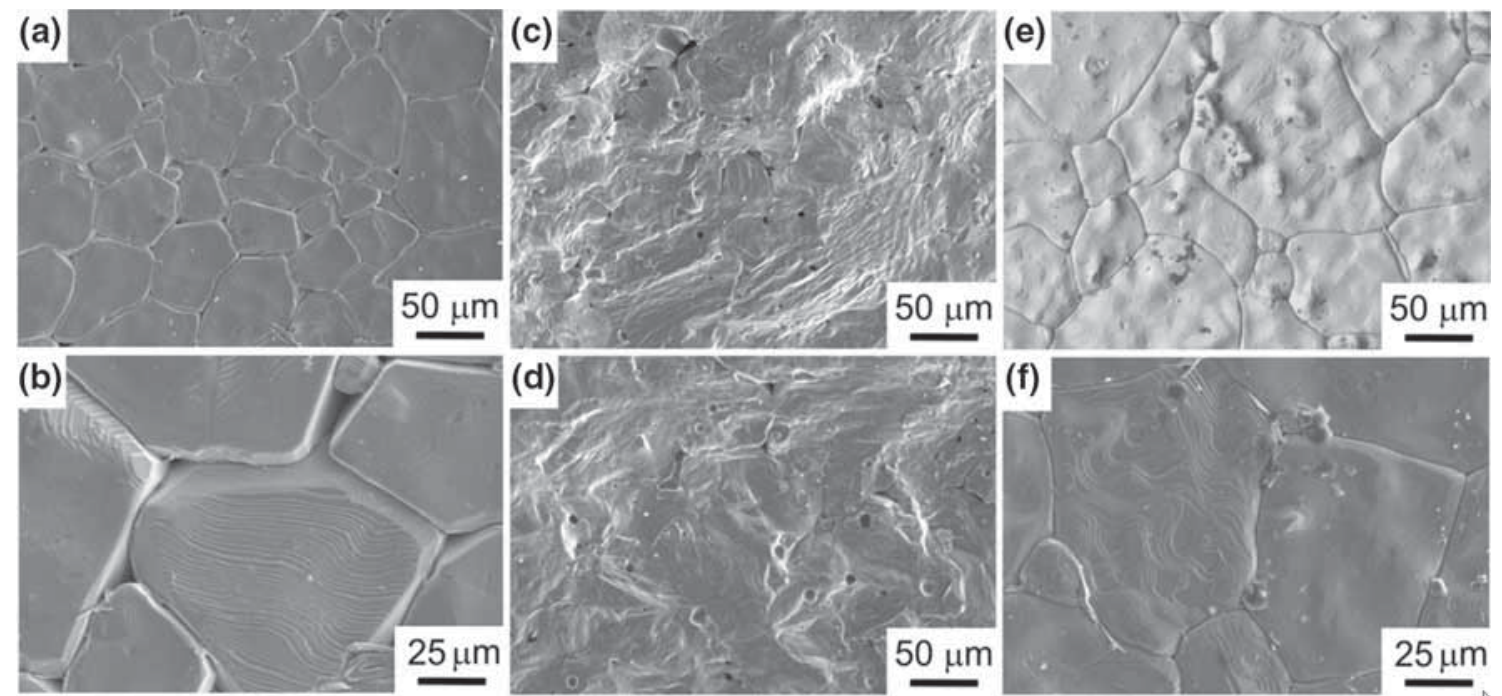

Figure 12. SEM microstructure of the BT_1 pellet surface at two different magnifications: $(\mathbf{a}) \times 350,(\mathbf{b}) \times 1000$; BT_1 fracture surface at two different magnifications: $(\mathbf{c}) \times 350,(\mathbf{d}) \times 500$ and BT_2 pellet surface at two different magnifications: $(\mathbf{e}) \times 500$, (f) $\times 1000$.
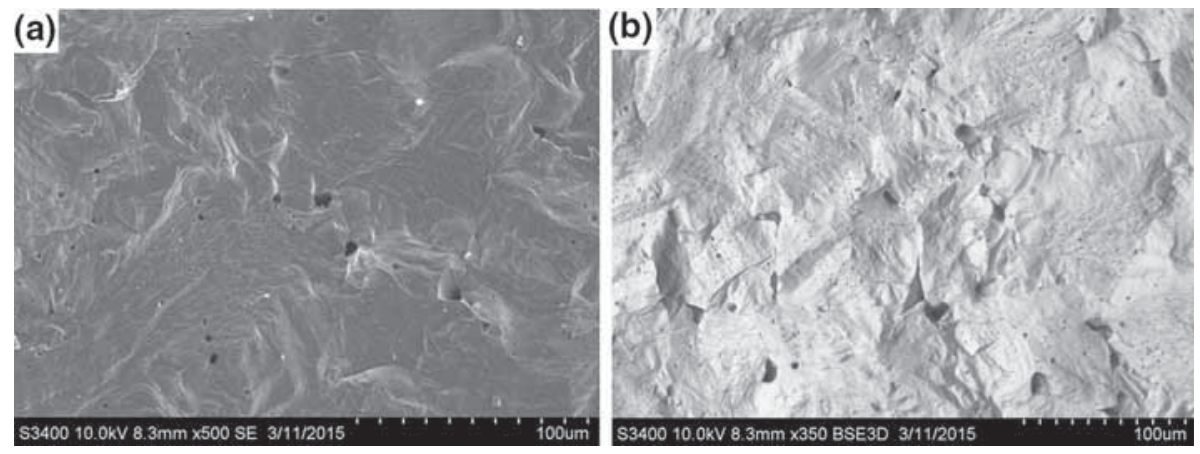

Figure 13. (a) Secondary electrons and (b) backscattered electron micrographs of BT_2 pellet fracture surface.
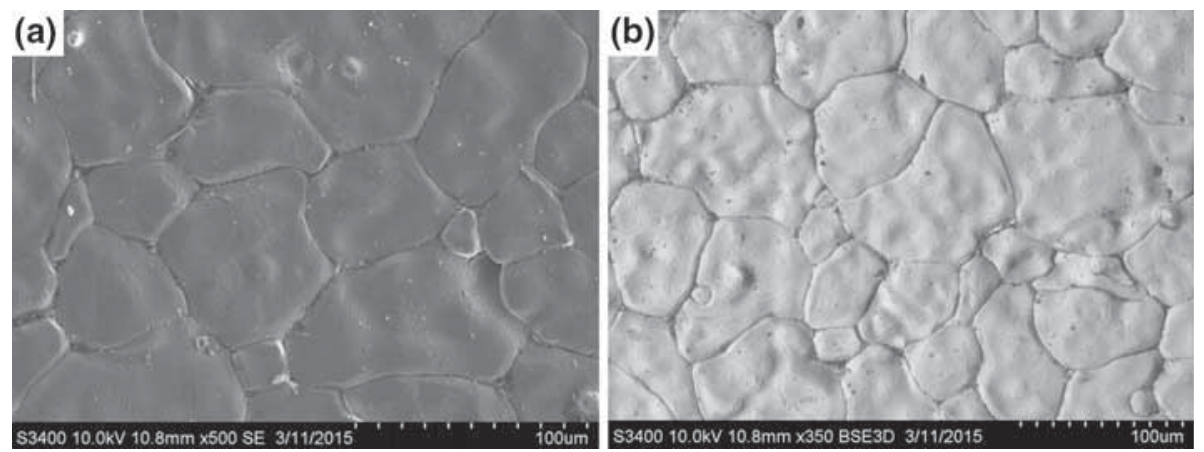

Figure 14. (a) Secondary electrons and (b) backscattered electron micrographs of BT_3 pellet surface. 

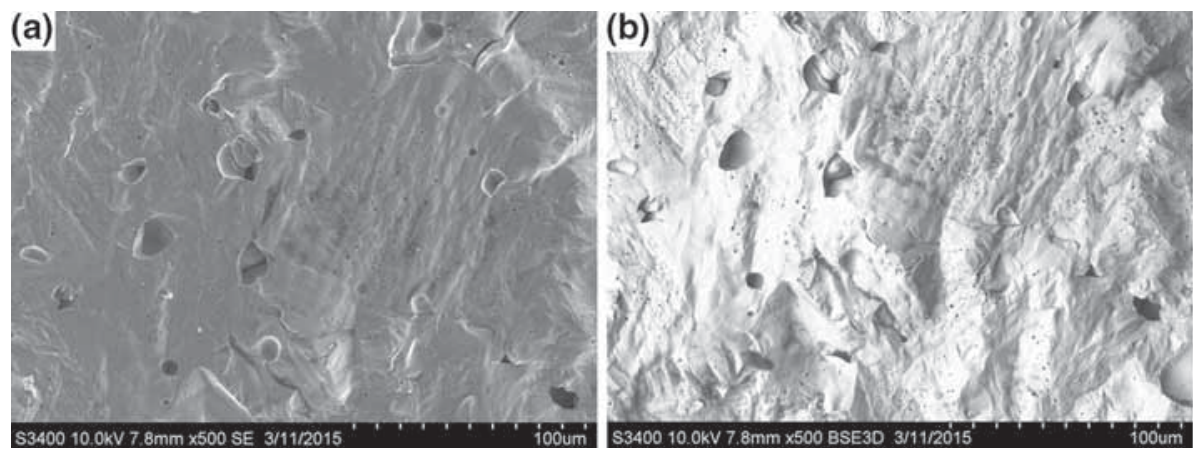

Figure 15. (a) Secondary electrons and (b) backscattered electron micrographs of BT_3 pellet fracture surface.
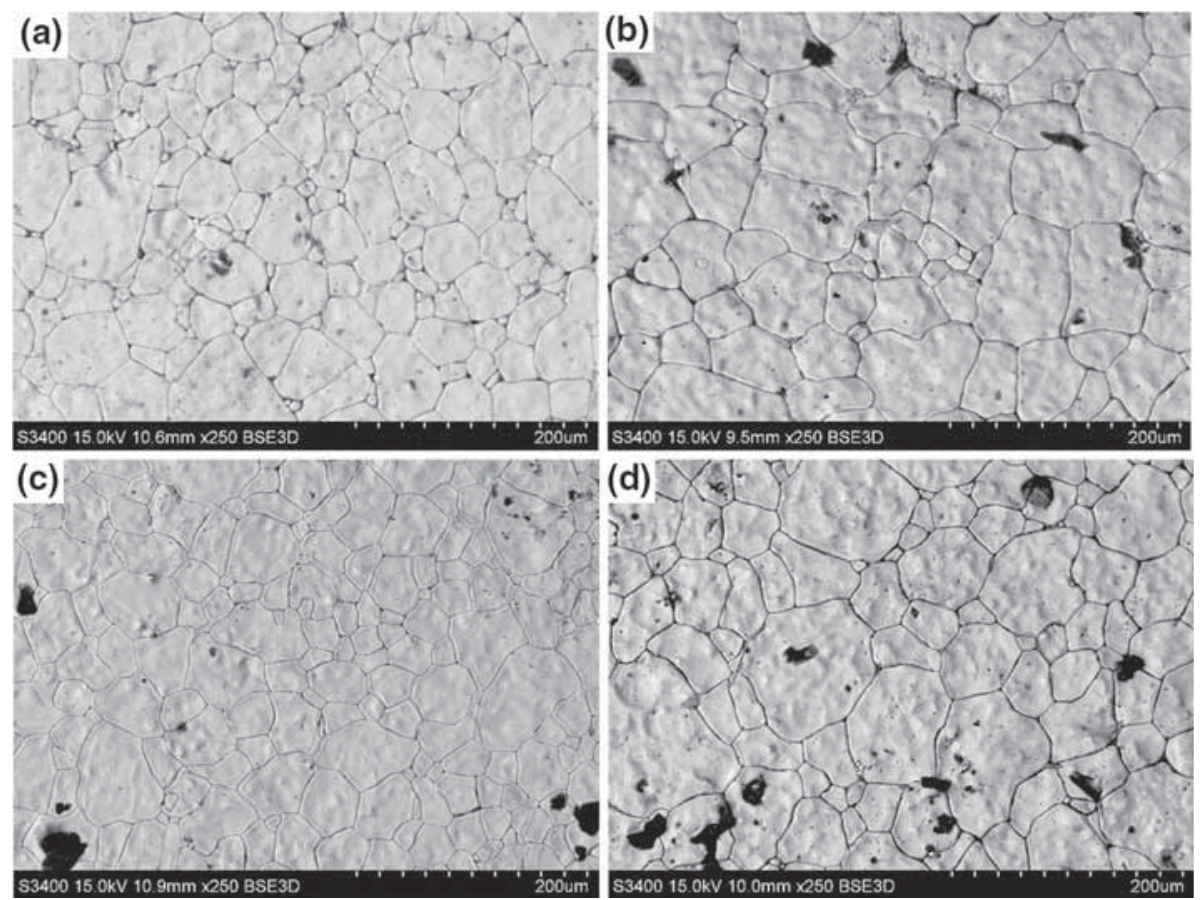

Figure 16. SEM microstructure of (a) BT_0, (b) BT_5, (c) BT_6 and (d) BT_7 pellets surface in the same magnification $\times 250$.

Table 6. The apparent density, water absorbability and apparent porosity of sintered pellets.

\begin{tabular}{lcccc}
\hline Material & $\begin{array}{l}\text { Water } \\
\text { absorbability (\%) }\end{array}$ & $\begin{array}{l}\text { Apparent } \\
\text { density }\left(\mathrm{g} \mathrm{cm}^{-3}\right)\end{array}$ & $\begin{array}{l}\text { Apparent } \\
\text { porosity (\%) }\end{array}$ & $\begin{array}{l}\text { Relative } \\
\text { density (\%) }\end{array}$ \\
\hline BT_5 & 0.01 & 5.77 & 0.05 & 95.85 \\
BT_6 & 0.02 & 5.76 & 0.11 & 95.68 \\
BT_7 & 0.01 & 5.76 & 0.04 & 95.68 \\
\hline
\end{tabular}

BT_0 thus exhibits normal dielectric dispersion because the dielectric constant $\left(\varepsilon^{\prime}\right.$ and $\left.\varepsilon^{\prime \prime}\right)$ decreases with increasing frequency. The phenomenon of dielectric dispersion is attributed to Maxwell-Wagner type interfacial polarization in accordance with Koop's phenomenological theory [41,42]. This theory states that the conductivity of grain boundaries 


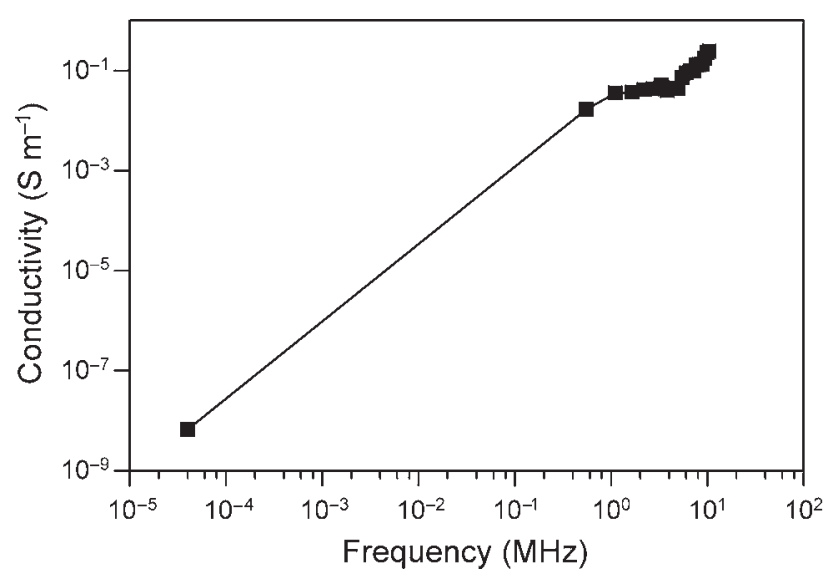

Figure 17. AC conductivity $v s$. frequency.

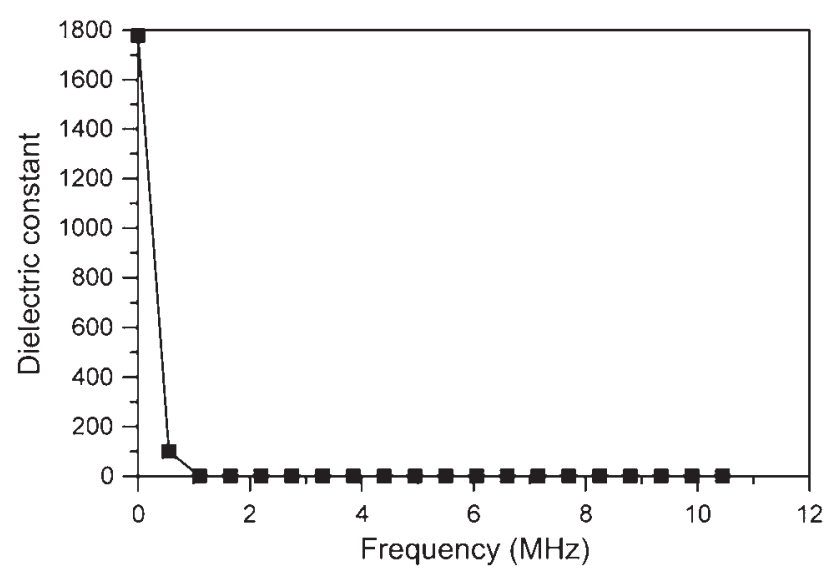

Figure 18. Dielectric constant $v s$. frequency.

contributes more to dielectric permittivity at lower frequencies and temperatures. The sintering of polycrystalline perovskite involves the formation of grains with high conductivity. These grains are separated by poorly conducting grain boundaries, as can been seen in SEM images, and exhibit low conduction; BT_0 perovskite thus behaves as a heterogeneous dielectric material.

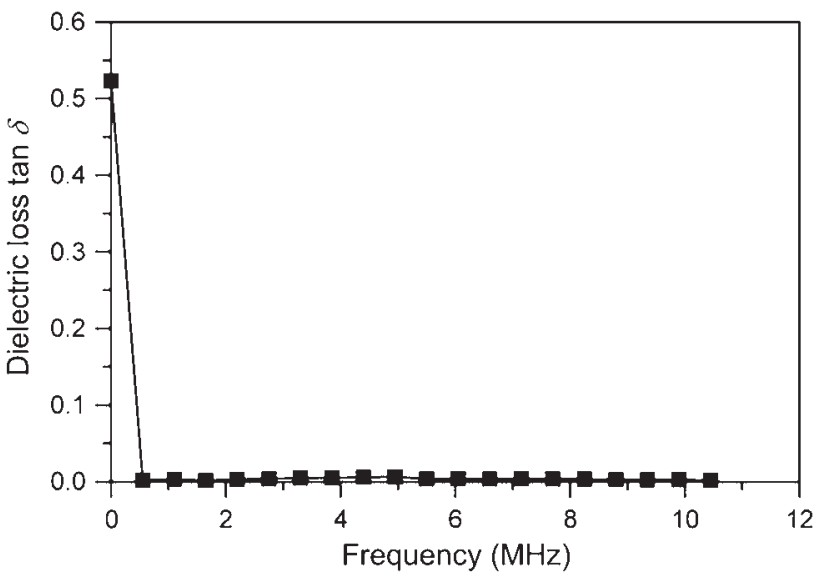

Figure 19. Dielectric loss vs. frequency.

In addition, $\mathrm{Ti}^{4+}$ is reduced to $\mathrm{Ti}^{3+}$ and formed a conduction electron $\left(\mathrm{Ti}^{4+} \mathrm{e}\right)$ to keep charge neutrality. It can be found that dielectric permittivity measured at lower frequency is always greater than higher frequency. With the increasing frequency, dielectric constant decreases very fast up to $10^{5} \mathrm{~Hz}$ and in frequency range from $10^{6}$ to $10^{7} \mathrm{~Hz}$ it is almost constant. The higher value of dielectric constant of 1700 may possibly also strongly depend on the density of the sample due to the sintering process of $\mathrm{BaTiO}_{3}$.

The dielectric loss represents a combined result of electrical conduction and orientational polarization of the matter. Figure 19 shows the variation of dielectric loss tangent $\delta(\tan \delta)$ with frequency for BT_0. The investigated material shows a normal dielectric behaviour. Dielectric loss tangent decreases with increasing frequency of the alternating field, and the maximum value of 0.5 was obtained at low frequencies. The permittivity loss curve at $30^{\circ} \mathrm{C}$ shows two relaxation peaks, which occurs when the frequency jumping of electrons $\mathrm{Ti}^{4+} \leftrightarrow \mathrm{Ti}^{3+}$ is equal to the frequency of the applied AC field $[43,44]$. Moreover, the values of $\tan \delta$ decrease at higher frequency in the range $0.007-0.001$. Therefore, the energy losses were due to conductivity and dipole relaxation. The loss factor $\tan \delta$ of a dielectric material is a useful indicator of the energy loss as heat.

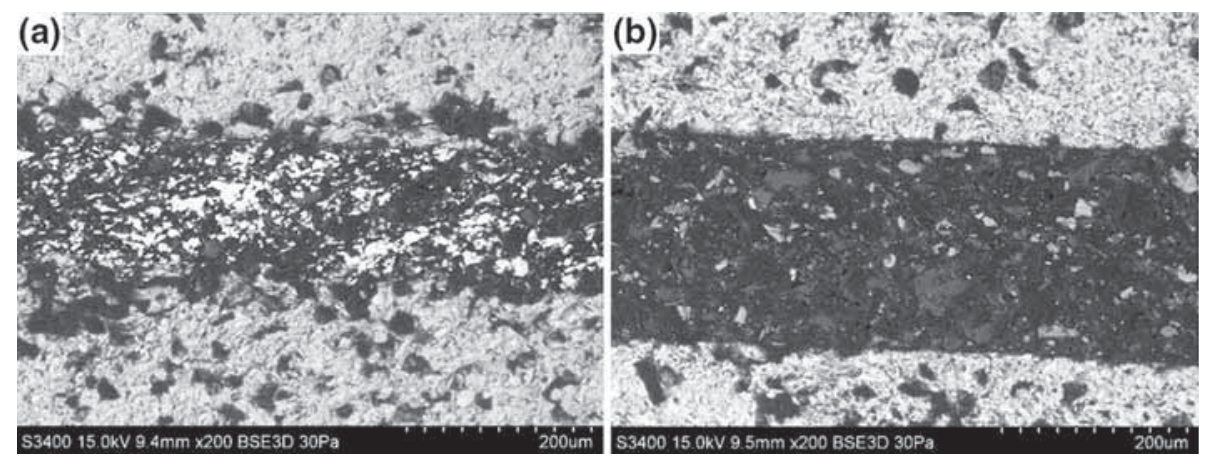

Figure 20. SEM images of (a) BT_0_S and (b) BT_0_M fracture surfaces at magnification $\times 200$. 


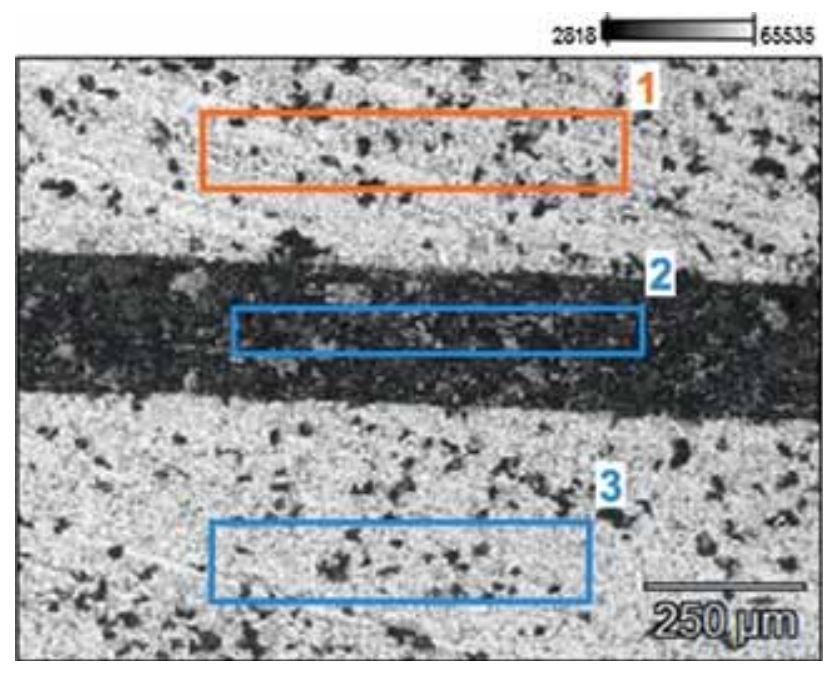

Figure 21. SEM microstructure of fracture surface of BT_0_M sample identifying three considered areas.

Table 7. The wt $\%$ of chemical elements presented in three areas of BT_0_S sample.

\begin{tabular}{lcccrrr}
\hline Area & O-K & Al-K & Si-K & Ti-K & Ag-L & Ba-L \\
\hline 1 & 17.5 & 2.3 & & 23.6 & & 56.5 \\
2 & 20.2 & 2.4 & 3.3 & 7.7 & 66.4 & \\
3 & 17.8 & 1.4 & & 23.5 & & 57.3 \\
\hline
\end{tabular}

\subsection{Characterization of barium titanate actuator}

Analysis of the top-most metallic layers deposited on the barium titanate pellets revealed their high quality at the macroscopic scale. However, in order to verify whether the bonding layers adhered well to the ceramic pellets, SEM images of fracture surfaces for BT_0_S (figure 20a) and BT_0_M (figure 20b) were obtained.

Considered fracture surfaces of BT_0_S and BT_0_M samples with indicated three areas under observation are presented in figure 21 for BT_0_M. Areas number 1 and 3 are placed on barium titanate ceramic and area number 2 is situated on bonding layers.

Tables 7 and 8 present results of wt $\%$ of chemical elements presented in these three indicated areas for BT_0_S and BT_0_M samples, respectively. As one can expect, on area numbers 1 and 3, Ba and Ti elements are presented and the weight percent of these elements is extremely similar in all areas. In the case of BT_0_S sample, the metallic layer is mainly composed of silver, which is also according to expectation. A small amount of $\mathrm{Si}$ in bonded layer comes probably from the applied product composition.

The chemical composition of Chester Molecular Metal Super was not presented on the product datasheet, but from data put together in table 8 it shows that this product is composed from $\mathrm{Fe}, \mathrm{Cr}$, Ti and $\mathrm{Si}$. It should be underlined that at
Table 8. The wt $\%$ of chemical elements presented in three areas of BT_0_M sample.

\begin{tabular}{llllllll}
\hline Area & O-K & Al-K & Si-K & Ti-K & Cr-K & Fe-K & Ba-L \\
\hline 1 & 19.5 & 2.4 & & 24.0 & & & 54.2 \\
2 & 24.1 & 4.6 & 22.3 & 12.8 & 25.4 & 10.7 & \\
3 & 18.2 & 1.3 & & 23.7 & & & 56.7 \\
\hline
\end{tabular}

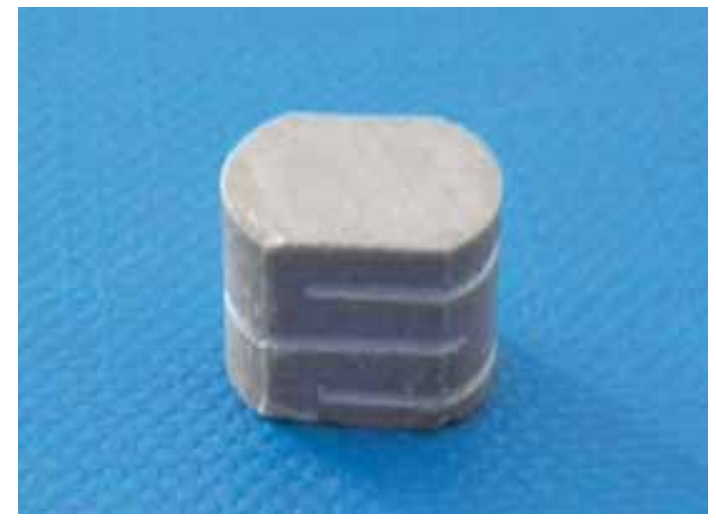

Figure 22. Actuator manufactured from barium titanate ceramic and three metallic layers.

both metallic layers Ti element is present, but it is not sure whether its appearance is connected with local migration from ceramic layers to a bonding one.

The first short actuator presented in figure 22 was made from a piece of BT_0 beams by cutting three gaps with a saw. Finally, these gaps are filled in by using Technicqll product to obtain metal layers.

\section{Conclusions}

The investigated material shows a normal dielectric behaviour. Dielectric loss tangent decreases with increasing frequency of the alternating field, and the maximum value of 0.5 was obtained at low frequencies. Interestingly, the sintering temperature did not considerably increase the size of grains. In this approach, the obtained sinter microstructure is extremely similar to the one presented in the literature by other authors. To receive a better result of the barium titanate dielectric constant, the microstructure of sinter must be improved in the direction of getting smaller grains.

The SEM images of both BT_0_S and BT_0_M samples reveal high quality ceramic-metallic-ceramic bonding, with extremely good adhesion properties and without any fractures. In the case of BT_0_S, additional intermediate layers between the barium titanate and metallic material were created. These thin layers should ensure better adhesion of appropriate materials. Therefore, Technicqll was selected for use in further investigations. 
In addition, SEM-EDS was employed in order to determine the chemical elemental composition of micro areas in selected layers. However, it should be noted that the utilized EDS unit is not suitable for oxygen elemental analysis, while the base on which the analysed samples were placed is composed of aluminium; therefore, these two elements should not be included in the analysis.

\section{Acknowledgements}

The research leading to these results has received funding from the People Programme (Marie Curie Actions) of the European Union's Seventh Framework Programme FP7/2007-2013/ under REA Grant Agreement No. PITN-GA2013- 606878 .

\section{References}

[1] Roy A C and Mohanta D 2009 Scr. Mater. 61891

[2] Vijatović M M, Bobić J D and Stojanović B D 2008 Sci. Sinter. 40235

[3] Zhao Z, Buscaglia V, Viviani M, Buscaglia M T, Mitoseriu L, Testino A et al 2004 Phys. Rev. B 70024107

[4] Upadhyay R H, Argekar A P and Deshmukh R D 2014 Bull. Mater. Sci. 37481

[5] Mahajan S, Thakur O P, Prakash C and Sreenivas K 2011 Bull. Mater. Sci. 341483

[6] Habib A, Stelzer N, Angerer P and Haubner R 2011 Bull. Mater. Sci. 3419

[7] Osman K I 2011 Synthesis and characterization of $\mathrm{BaTiO}_{3}$ ferroelectric material $\mathrm{PhD}$ Thesis

[8] Stojanovic B D, Foschini C R, Pavlovic V B, Pavlovic V M, Pejovic V and Varela J A 2002 Ceram. Int. 28293

[9] Yu P, Wang X and Cui B 2007 Scr. Mater. 57623

[10] Miot C, Proust C and Husson E 1995 J. Am. Ceram. Soc. 15 1163

[11] Kholodkova A, Danchevskaya M and Fionov A 2012 In Proceedings of the nanocon conference $\mathrm{p} 134$

[12] Kao C F and Yang W D 1999 Appl. Organomet. Chem. 13383

[13] Kržmanc M M, Klement D, Jančar B and Suvorov D 2015 Ceram. Int. 4115128

[14] Gaytan S M, Cadena M A, Karim H, Delfin D, Lin Y, Espalin D et al 2015 Ceram. Int. 416610

[15] Chen J F, Shen Z G, Liu F T, Liu X L and Yun J 2003 Scr. Mater. 49509
[16] Brzozowski E and Castro M S 2003 Thermochim. Acta 398 123

[17] Pavlović V P, Nikolić M V, Nicolić Z, Branković G, Živković L, Pavlović V B et al 2007 J. Eur. Ceram. Soc. 27575

[18] Kong L B, Ma J, Huang H, Zhang R F and Que W X 2002 J. Alloys Compd. $\mathbf{3 3 7} 226$

[19] Nicolić M V, Pavlović V P, Pavlović V B and Ristić M M 2006 Sci. Sinter. 38239

[20] Kim Y J, Hyun J W, Kim H S, Lee J H, Yun M Y, Noh S J et al 2009 Bull. Korean Chem. Soc. 301267

[21] Kim B J, Park T G and Kim M H 1998 J. Korean Phys. Soc. 32 S289

[22] Steele B C H 1991 Electronic ceramics (Amsterdam: Elsevier)

[23] Richerson D W 1992 Modern ceramic engineering: properties, processing, and use in design (New York: Marcel Dekker Inc.)

[24] Newnham R E and Trolier-Mckinstry S E N 1990 Ceram. Trans. 8235

[25] Park Y and Kim H 1997 J. Am. Ceram. Soc. 80106

[26] Stojanovic B D, Foschini C R, Zaghete M A and Veira F O S 2003 J. Mater. Process. Technol. 143-144 802

[27] Benlahrache M T, Benhamla N and Achour S 2004 J. Eur. Ceram. Soc. 241493

[28] Vittayakorn N 2006 J. Appl. Sci. Res. 21319

[29] Hang T, Glaum J, Genenko Y A, Phung T and Hoffman M 2016 Acta Mater. 102284

[30] Biglar M, Gromada M, Stachowicz F and Trzepieciński T 2015 Acta Mech. 2663451

[31] Jiang W, Devanathan R, Sundgren C J, Ishimaru M, Sato K, Varga T et al 2013 Acta Mater. 617904

[32] Hu J and Shen Z 2015 Scr. Mater. 10714

[33] Wang J C, Zheng P, Yin R Q, Zheng L M, Du J and Zheng L 2015 Ceram. Int. 4114165

[34] Cai W, Fu C, Lin Z and Deng X 2011 Ceram. Int. 373643

[35] Zheng P, Zhang J L, Tan Y Q and Wang C L 2012 Acta Mater. 605022

[36] He F, Ren W, Liang G, Shi P, Wu X and Chen X 2013 Ceram. Int. $39 \mathrm{~S} 481$

[37] Duran P, Gutierrez D, Tartaj J and Moure C 2002 Ceram. Int. 28283

[38] Yoon D H and Lee B I 2004 J. Eur. Ceram. Soc. 24739

[39] Wang J C, Zheng P, Yin R Q, Zheng L M, Du J, Zheng L et al 2015 Ceram. Int. 4114165

[40] Park J H, Yoo D H, Kim C S, Yang H S, Moon B K, Jung G J et al 2006 J. Korean Phys. Soc. 49 S680

[41] Hilborn Jr R B 1965 J. Appl. Phys. 361553

[42] Koops C G 1951 Phys. Rev. 83121

[43] Chanmal C V and Jog J P 2008 Express Polym. Lett. 2294

[44] Batoo K M, Kumar S, Lee C G and Alimuddin 2009 Curr. Appl. Phys. 9826 